\title{
Introducing a New Series: Biology and Impacts of Pacific Island Invasive Species
}

INVASIVE SPECIES from across a broad taxonomic spectrum have affected the ecological integrity, human economies, and quality of life in the Pacific islands. In fact, to a large degree, problems caused by invasive species in the Pacific islands represent a stark warning for the rest of the planet, demonstrating the extent to which habitats can be compromised by invasive species. Many researchers are actively working on individual species, and some research summaries are available on the Internet, but no comprehensive, peerreviewed repositories exist for in-depth biological information on Pacific island invasive species. With this issue of Pacific Science, we are introducing a new series entitled "Biology and Impacts of Pacific Island Invasive Species" that we hope will fill this gap. Each article in the series will provide researchers and managers with a review of research from a wide variety of sources on a particular invasive species of the Pacific islands, detailing various aspects of the biology, impact, and management of the species.

The first article in the series, which immediately follows this notice, is by Warren Hays and Sheila Conant on the small Indian mongoose (Herpestes javanicus). Their review illustrates the value of assembling a large amount of information within a single source. Hays and Conant find that although mongooses are found on eight Pacific islands (and many other islands throughout the world), the precise impact of the animal on native fauna and flora is not always clear, and management of mongoose populations is no simple matter. Likewise, we are starting to get a wide-ranging picture for many other species, terrestrial and aquatic, that threaten Pacific island ecosystems and economies. This picture would be brought into sharper focus

Pacific Science (2007), vol. 61, no. 1:1

(C) 2007 by University of Hawai'i Press

All rights reserved through reviews that assemble existing studies and encourage further research.

Researchers interested in contributing an article to the series should make an offer to the series editor, David Clements, Department of Biology, Trinity Western University, 7600 Glover Road, Langley, British Columbia, Canada, V2Y 1Y1 (e-mail: clements@ twu.ca). Offers can be made by individuals or groups and should include the following: (1) the proposed species, (2) why a review of this species represents an appropriate and important contribution to the Biology and Impacts of Pacific Island Invasive Species Series, and (3) details of the qualifications of the author(s) in terms of writing the review. The series editor will consult with experts within the proposed subject area and the editor-inchief to determine if the species account is appropriate to the series. If the offer is approved, the author(s) will be expected to complete the review within 2 years, and the submitted manuscript will be subjected to the usual Pacific Science review process and page charges. Detailed instructions to authors, including the format for the series, will be available on the Pacific Science Web site (http://www.uhpresshawaii.com/journals/ ps/). Prospective authors may also want to examine other articles in the series and/or consult the series editor regarding formatting.

We welcome proposed contributions to the Biology and Impacts of Pacific Island Invasive Species Series, and we trust that the new series will provide researchers and managers in the Pacific islands with a valuable resource. Sun Tzu, a Chinese general ca. 500 B.C., was quoted as saying "Know thine enemy as thyself and thou shalt be victorious." There is certainly much yet to be learned about the invasive species that are spreading throughout the Pacific islands.

David R. Clements, series editor (clements@twu.ca) Curtis C. Daehler, editor-in-chief, Pacific Science 
